\title{
Teaching One Health: Animal husbandry in a post-graduate interdisciplinary curriculum
}

Djibo Idrissa Sidikou ${ }^{1}$, Yannick Caron ${ }^{2}$, Catherine Delguste ${ }^{3}$, Abdoulkarim Issa Ibrahim ${ }^{4}$, Maman Laminou Ibrahim ${ }^{5}$, Hassane Adakal ${ }^{1}$, Jean-Luc Hornick ${ }^{3}$ and Nicolas Antoine-Moussiaux ${ }^{3}$

1. Department of Animal Sciences and Techniques, Faculty of Agricultural and Environmental Sciences, University Dan Dicko Dankoulodo of Maradi, Maradi, Niger; 2. Unit of Veterinary Diagnostic, Qualys Tulle, France; 3. Fundamental and Applied Research for Animals and Health, Faculty of Veterinary Medicine, University of Liège, Liège, Belgium;

4. Department of Animal Productions, University Boubakar Bâ of Tillabéri, Niger; 5. Centre de Recherche Médicale et Sanitaire (Medical and Health Research Center), CERMES, Niamey, Niger.

Corresponding author: Djibo Idrissa Sidikou, e-mail: dsidikou@yahoo.com

Co-authors: YC: yannick.caron@qualyse.fr, CD: cdelguste@uliege.be, AII: karimlebelge@yahoo.fr,

MLI: lamine.cermes@gmail.com, HA: hassaneadakal@gmail.com, JLH: jlhornick@uliege.be, NA: nantoine@uliege.be Received: 16-01-2020, Accepted: 28-04-2020, Published online: 09-06-2020

doi: www.doi.org/10.14202/IJOH.2020.69-75 How to cite this article: Sidikou DI, Caron Y, Delguste C, Ibrahim AI, Ibrahim ML, Adakal H, Hornick J-L, Antoine-Moussiaux N (2020) Teaching One Health: Animal husbandry in a post-graduate interdisciplinary curriculum, Int. J. One Health, 6(1): 69-75.

\begin{abstract}
Background and Aim: This work presents the implementation of a course on animal husbandry in an interdisciplinary curriculum based on the One Health concept. The study describes learners' viewpoints about the course and its insertion in the curriculum. The study aimed at identifying avenues for improvement.

Materials and Methods: Fourteen learners (health professionals) participated to individual semi-structured interviews lasting for 25-35 min each. Learners' opinions were extracted from the transcribed interviews and analysis themes were identified from recurrent narratives.

Results: The learners perceived animal husbandry as relevant for One Health and potentially useful for their future practice. More precisely, learners were considering a future use of the newly acquired knowledge and skills in the advising of communities facing malnutrition and for the strategic planning at wider levels. Teaching methods were appreciated thanks to the active learning style. Unmet expectations concerned the coverage of impacts and relationships to other disciplines, the inclusion of viewpoints from other disciplines into the teaching, and the degree of contextualization of contents, e.g. through case studies. Accordingly, the main avenues for improvement, as identified by learners, were to give a prior focus on impacts (especially on human health) for all contents and to increase the number of case studies, but also to better address the questions of the usefulness of animal products in the management of malnutrition.
\end{abstract}

Conclusion: The analysis of learners' expectations (met and unmet) and their recommendations regarding the future of the course helped identifying both successes and important challenges for teachers. Two main challenges are highlighted. First, increased interdisciplinarity is needed within the course to better cover the notion of impact of animal husbandry on health, society and environment. Second, the complexity of the domain under consideration will call for important efforts of clarification of the course structure and objectives in terms of skills acquisition.

Keywords: animal husbandry, curriculum, interdisciplinarity, one health.

\section{Introduction}

The One Health concept considers health issues at the interface between humans, animals, and the ecosystems they share. During the last decades, the growing recognition of the need to build bridges between human, animal, and environmental health sectors led, in 2010, to a tripartite agreement between the World Health Organization, the World Organization for Animal Health, and the Food and Agriculture Organization [1]. Since then, efforts have been sustained for the development of curricula to train a

Copyright: Sidikou, et al. This article is an open access article distributed under the terms of the Creative Commons Attribution 4.0 International License (http://creativecommons.org/licenses/ by/4.0/), which permits unrestricted use, distribution, and reproduction in any medium, provided you give appropriate credit to the original author(s) and the source, provide a link to the Creative Commons license, and indicate if changes were made. The Creative Commons Public Domain Dedication waiver (http:// creativecommons.org/ publicdomain/zero/1.0/) applies to the data made available in this article, unless otherwise stated. next generation of One Health practitioners with the needed competencies in terms of interdisciplinary and intersectoral collaboration. While the One Health concept is often mobilized around issues of zoonotic threats and antimicrobial resistance, one shouldn't neglect the importance of this approach in tackling malnutrition and its related disease burden as child growth retardation or death [2]. Domesticated animals directly provide food or contribute to agricultural workforce, as well as to soil fertility management. For many households, animals also constitute an asset that is key to their financial security, allowing to cover basic needs, as food purchase and access to health care. Furthermore, in small-scale agriculture, livestock is often linked to the empowerment of women and strengthening of civil society [3]. Naturally, animal husbandry also intervenes in the here-above mentioned challenges of zoonotic risks and antimicrobial resistance. Moreover, animal production is itself 
severely compromised in many regions of the world by animal diseases, while environmental harms are both ascribed to livestock and affecting livestock [4]. For all these reasons, a reflection on animal husbandry would take a central role in a One Health approach, to favor the health benefits of livestock, protect animal health and secure livelihoods, and promote environmental sustainability.

To contribute to the building of a One Health approach, new programs for training and research are developed worldwide targeting improved interdisciplinary and intersectoral collaborations $[5,6]$. The mechanisms of curricula development, the logic of the courses choice, the choice of teaching methods, or learners profiles constitute parameters that can be specific to each training program. An assessment of a new One Health curriculum was described by Eveillard et al. [7]. Their study was focused on the evaluation of the integration of a course on microbiology and infectious disease in a "One World, One Health" oriented master program. They pointed out complexities that influence the success, among which can be cited the course orientation, the teaching methodologies, the cohesion of learners, and their involvement. The present study proposes to parallel this investigation, focusing on the inclusion of a course on animal husbandry in a One Health curriculum.

\section{The master program}

The master in Integrated Management of Health Risks in the Global South is a One Health-oriented post-graduate master program carried out in Belgium. This one-year program aims at introducing the need and methods for a better integration of human, animal, and environmental health to an audience composed of health professionals from the Global South. To operationalize the concept, the curriculum was based on the review of concrete health issues, whether specific or not to developing countries. These issues were articulated around five inter-linked themes: zoonotic diseases, antimicrobial resistance, food security and safety, ecosystem disturbances, and land planning. The program is led by three Belgian universities and other non-academic partners.

This study was conducted during its first year of implementation, i.e. 2016-2017. Participants were physicians, veterinarians, and agronomists. The program includes 5 months of teaching activities followed by a 2-month field application in partner institutions, at the national or international level.

\section{Teaching activities on animal husbandry}

A teaching unit was developed to gather contents linked to animal husbandry and was entitled: "Animal production in the Global South and its health, social and environmental impacts". The course was composed of five components. Component 1 proposed an overview of stakes around family farming in low and middle income countries. The main objectives of component 1 were to set the overall picture of the relationships between farming and health, to discuss basic concepts (e.g. sustainability, pillars of food security), and to develop a critical knowledge about its insertion in national and international strategies. Component 2 provided a closer look at the question of protein sources, among which of animal origin and alternatives sources. The diverse aspects of meat consumption and alternatives were covered (from definition, production, nutritional contribution, to environmental impact or legislation). Component 3 covered issues in animal nutrition, as feed value, carrying capacity of pastures, or energy transformation according to Hemmingsen [8]. This component highlighted the important trade-offs in tackling issues of land and natural resource allocation within national strategies for food security including the animal sector. This component included a field visit of innovative integrated goat breeding system for milk production (small integrated organic farming), followed by discussion and comparison with learners experiences, and extended interactive exchange. Component 4 covered the sector of aquaculture and its technical integration into agriculture. The aim was to open the scope of animal production, pinpointing the important role played globally by aquaculture. This component was more particularly to highlight links between production, environment and human health. Component 5 brought an additional viewpoint in this same prospect, focusing on extensive management of grasslands.

Teaching methods were based on expert presentations, classroom discussion and exchange of experiences, e-learning sessions, problem-based learning with case scenarios, and field visits. Pair or groups were often mobilized, involving learners from at least two different profiles.

Course evaluation was based on a problem-solving exercise, where students had to propose strategies: 1) to insure food security in case of sanitary crisis or natural disaster, and 2) to evaluate risks in terms of health, equity and environmental impacts for a national food security strategy. This work was subject to oral presentation and questioning by a jury.

\section{Materials and Methods}

\section{Ethical approval and informed consent}

Each learner signed an informed consent to participate to the study. The consent document stated the conditions of the study, i.e. the guarantee of anonymity and the restriction of the use of results for scientific publication. The object and nature of the study did not require any formal ethical approval by an official commission.

\section{An immersive survey}

The first author of the study, who conducted the whole process of interview and data analysis, has followed the complete master program, being duly enrolled for degree completion. Beyond the acquisition of new competencies, the stated goal for this 
enrollment was to analyze and translate pedagogic orientations in a program to be developed in Niger, where the first author holds an academic position. This survey is part of a wider endeavor covering the complete pedagogic strategy of the program. However, the envisioned program in Niger being centered on animal husbandry, this explains the particular focus of this paper.

\section{Data collection and characteristics of respondents}

The perceptions of the 14 learners were collected after completion of the teaching unit. Among the 14 respondents, seven were physicians, five were veterinarians, and two were agronomists (one expert in animal production, and one in general agronomy).

Semi-structured individual interviews, lasting 25-35 min, were conducted using an interview guide, organized around the following themes: perceived interest of the content for One Health in general, personal usefulness of acquired knowledge, expectations that were not met, suitability of teaching activities. Interviews were tape-recorded and fully transcribed. The whole process was conducted in French, that is the teaching language of the program.

\section{Data analysis}

Data analysis consisted of an inductive analysis of narratives, according to the principles of grounded theory $[9,10]$. Recurrent themes were identified across narratives and their joint interpretation was conducted to extract main observations about the course perception and its benefits for the learner.

\section{Results}

\section{Course appreciation and diversity of profiles}

Learners' major viewpoints are synthesized in Figure-1. All learners had appreciated the opportunity to work and share knowledge with other learners coming from various professional backgrounds and cultures. They also strongly appreciated acquiring new knowledge in unexpected areas and various disciplines. Being supervised by experienced teachers also appeared as a strongly appreciated point. No link between the learner profile and the overall satisfaction could be noticed, the diversity of views being shared across professional backgrounds and nationalities. As developed here below, the professional background had influenced expectations and the personal use envisioned for the newly acquired skills and knowledge.

\section{Learners' expectations}

Based on the professional backgrounds, learners had been able or not to formulate expectations prior to the course. Learners from human medicine lacked references about the issues around animal husbandry and entered into the course without a priori expectations beyond finding out the usefulness of the content for the One Health approach.

Only two respondents manifested a complete satisfaction, stating that "all have been covered". Regarding unmet expectations, three respondents would have expected more about "impact on human health", suggesting a probable difficulty to make this link between several course elements and human health. A related request was also made for an intervention of medical specialists within this course, in order to convey the "vision of a doctor" on these topics. Beyond this request for an input of the medical domain, both learners with and without background in animal husbandry called for contributions of a wider range of experts to better achieve the courses objectives: "all participate to the concept; in case of problem, we have to see all contributions and find out what can help."

A call for more "contextualized" content was also expressed, indicating that the share of abstract contents had been even more difficult to grasp in their meaningfulness for field practitioners. The term of "contextualization" also appeared in an expectation expressing the need for more directly applicable contents: "I expected methodology of contextualization to address climatic change in our countries and how to improve animals feeding".

Subjects covered under the course were also mentioned in the list of unmet expectations, indicating a request for in-depth knowledge on these topics: pasture management, input quality, or food-related risk.



Figure-1: Learners' major viewpoints about animal husbandry course in One Health-based curriculum. 


\section{Appreciation of relevance of the course in the curriculum}

Twelve respondents clearly stated the relevance of animal husbandry for the curriculum, six of them mentioning explicitly the "direct usefulness to improve human health". One was more nuanced and one clearly expressed a divergent opinion, acknowledging however that "it may be useful in general".

Learners fully acknowledging the relevance of the course had put a special emphasis on animal feeding in their answers. This can be illustrated through the following assertion: "It is a good teaching unit, because improving animal feeding can improve also food intended for humans; therefore, one improves human health". A medical doctor further stated: "Before, I knew almost nothing about this, but the teachers helped us opening our mind and eyes; now I understand the importance of animal feeding for human". Nonetheless, other declarations could consider the course beyond its component on animal nutrition, as for example: "Now I understand why animal productions area is not well develop in our countries".

Narratives also allowed identifying the importance of previous learning in the good appreciation of this course. Indeed, the course being taught in the second semester, learners had already followed a wide range of courses allowing them to easily connect different courses and disciplines. Hence, one respondent expressed having experienced difficulties in perceiving the interest: "at the beginning, when you do not belong to this field, you wouldn't see the interest, but we had learned about One Health and understood that it is useful for the training".

\section{Appreciation of relevance for personal future practice}

Contents were not perceived as interesting for their direct technical implementation in future practice. Those were perceived as intellectual contributions to the understanding of issues and planning of solutions, which indeed fits the objectives of the course. Learners with human medicine profiles envisioned an advisory use of the newly acquired knowledge: "we can give advices to our communities, so they can improve herd productivity and product quality in order to fight against malnutrition, because it is a real problem". Three respondents commented on such a value-added in the handling of malnutrition. For one of them, "by solving a basic problem of animal feeding, a problem of malnutrition can be solved", and another pointed to "the quality of products such as meat or eggs, which the doctors also must understand because of its usefulness in the care of malnutrition".

\section{Appreciation of teaching methods}

Beyond the direct appreciation of interactive teaching methods or field visits, learners highlighted avenues for improvement, especially to "facilitate their understanding" and "stimulate their interest". The most cited avenue, mentioned 7 times, was to always underline first and foremost the "impact of animal husbandry on animal-human-environment health" and "relationships", before detailing technical contents. The second avenue, cited 5 times, was to better develop the contribution of "animal products quality and use for the management of malnutrition". A third avenue, cited 2 times, was to situate the content in concrete cases, referring to contextualization and use of case studies. Two last proposals were to better explore the "antagonism between mobilizing resources for animal feed or directly for human food" and to reduce contents that were felt as "purely technical", that "will not be useful for many of us", so that one "would not retain it, or would retain but would not use it". As opposed to these technical "details", the notion of production system attracted some interest and seemed to require a better handling in the course.

The first and the second avenues show again the importance that learners ascribe to the direct link between animal husbandry and human health. One respondent declared: "see it first in the one health context, showing the impact of animal husbandry in humans, and then put all together".

\section{Discussion}

\section{Overview of study outcomes}

The study describes learners' viewpoints on a course about animal husbandry within a One Health curriculum. It builds on the analysis of qualitative data to propose improvement avenues. The first author of this study being one of the learners, this status and full integration in the student cohort allowed him to perceive details about all teaching and learning process, to live the same learning situations, and hence to better understand learners' feelings and perceptions.

Learners' appreciation of the teachings lies within a scope of continuous improvement. Return from learners is useful to identify strengths on which the teaching can rest, or to underline weaknesses to improve. Before this publication, the present results have indeed been mobilized in the continuous improvement of the program. Health professionals following the course fully acknowledged the relevance of animal husbandry within a "One Health" concept that recognizes itself the diversity of disciplines to be involved in human health improvement [11]. They further identified the practical interest for their future practice and pointed to improvement avenues that, indeed, highlight their correct understanding of the One Health concept and the informed formulation of expectations.

This positive perception seems to indicate that the central objective of the course has been met. This success is even more appreciable in the case of medical doctors without any background in the domain nor perspectives in the direct implementation of technical skills. Indeed, this points out learners' capacity to appropriate knowledge that is radically new to them and integrate those into their foreseen practice. The key learning here appears to be the deep understanding 
of the relevance of a diversity of domains for health, and the need to collaborate with a wide spectrum of specialists in solving real life cases.

\section{Perceived relevance in the curriculum}

Curriculum making is a creative solution to societal problems, which calls for the involvement of a variety of expertise, referring to the famous saying "The world has problems, and universities have departments". Hence, interdisciplinary curriculum is used to provide learners an opportunity for more relevant, less fragmented, and stimulating experience [12]. Therefore, the relevance of a curriculum rests on the connections it is able to create between domains. In the present case, learners' narratives highlight their ability to identify such links and their willingness to deepen the questions around interdisciplinary interactions rather than the internal details of a given domain. They also expressed an interesting need to be accompanied in this challenge, with the particular proposition to introduce in the animal husbandry course the intervention of partner domains in order to give a more accurate account of these connections.

As illustrated here with the case of feed formula calculation, topics that are first perceived as internal to a domain fail to stimulate an unanimous interest among learners. Nevertheless, confronting this first misunderstanding is needed to help the learner discover the links to other domains and raise interest and even enthusiasm. In the meantime, some contents might appear too dissuasive and impede this discovery of links and connected usefulness. Thus, strategies have to be designed to lower these hurdles and facilitate the entry of students in totally new domains.

\section{Perceived usefulness for future practice}

According to Jacobs [12], when a curriculum is properly designed and when criteria for excellence are met, then learners break with the traditional view of knowledge and begin to actively foster a range of future perspectives. In the present work, learners without background in the concerned field identified that advising of communities and strategic planning are perspectives for a practical use of the acquired knowledge. This might partially indicate the efficacy of the curriculum design in facilitating the development of these new skills [13]. However, the present study points to a relative lack of skills identification by learners. Skills to teach must be clearly identified and directly related to the course content to allow learners to focus on the challenging learning activities and find the way to develop these skills $[13,14]$. According to Entwistle and Ramsden [15], the structure of a discipline is also necessary for knowledge acquisition, it is fundamental to learn how things are related. Moreover, perceiving clearly the goals and opportunities for autonomy in learning may help learners approach a new discipline with improved confidence and positive attitudes [15]. In the present case, this study having been conducted on the first year of implementation of the program, the clarity in the course structure and intended skills was still incompletely formalized.

\section{Met and unmet expectations}

Jacobs [12] considers that the teacher should be empowered to work as a designer, to shape and to edit the curriculum to fit learners' needs. An important question is then whether learners' expectations correctly represent their needs. This correspondence is itself a result from an in-depth understanding that is needed for someone to be able to identify his or her needs to progress in a given domain, here the One Health approach. In the present study, several unmet expectations can be regarded as considered in other courses. The fact that those are raised as expectations in the case of this course may be interpreted as a request to facilitate the linkages between courses, with interesting linkages being indeed partly identified by learners. This, again, is both a sign of the success of the course in proposing animal husbandry as interesting piece in the set of needed domains for One Health implementation and a sign that improvements within the course have to be pursued for the facilitation of interdisciplinary linkages. Each discipline develops a set of teachable knowledge with their own background of education, training, procedures, methods, constituting a reproducible internal coherence, or silo [16]. What is here needed for the teacher is to give up aspects he or she may deem essential to the domain to allow going beyond the established corpus. The need is at the same time to open breaches in the internal coherence of the domain and build bridges with the internal logic of other disciplines to facilitate the later interdisciplinary effort of the learner. Obviously, this process creates a challenge for its formal clarification in the course structure, as already mentioned here above.

This need for breaches and bridges entails that teachers from different disciplines should exchange on shared topics, expose their expertise but also the limits of their knowledge and give up some of their strength to free up space to others'. Yet, Jacobs [12] highlighted the issues emerging when topics can be covered in different courses, which may generate tensions among teachers due to some territoriality of science and expertise. In the same way, Melard et al. [17] identified in their study a system they called the "triad" that was composed by learners, teaching staff, and the protagonists of a problematic situation. This triad was shown to require a reconfiguration of the respective role of the three actors that could be problematic in the developing stage of the teaching.

\section{Teaching methods}

The teaching methods were appreciated thanks to the numerous interactions and problem-based approaches. Such active methods are believed to ease the exploratory approach of domains, enriching 
learners' understanding of a problem, and the development of their performance in reflexivity, as also shown by Mélard et al. [17]. The field visit in a local farm was interestingly highly appreciated, despite a double distance with the learners, in terms of discipline and context of operation. In fact, the farmer had prepared and participated to several on-farm activities with learners, and engaged at the end of those in the contradictory debate in which he had to defend his integrated farming, husbandry choices and his trust in the transferability of his precepts. Hence, through this activity, learners were engaged in a real-life exercise, being challenged in some of their convictions and realizing the need to gain competencies to judge about the relevance of a proposed model of food security. Still referring to the works of Melard et al. [17], this activity may pertain to a brief version of "public-based learning" in a triad composed of the learners, the teaching staff, and the farmer.

\section{Conclusion}

The learners perceived animal husbandry as relevant for One Health and potentially useful for their future practice. The course was thus successful in creating an overall interest for the domain, while highlighting the need for the health professional to collaborate with specialists when this will be needed. However, this first edition of the course was far from stabilized and two central challenges can be pinpointed in this conclusion. First, the internal balance of the course had to be deeply revised to allow for a better coverage of the linkages it was aiming at. This was needed to facilitate the development of interdisciplinary skills by learners but needs itself important interdisciplinary efforts from teachers. Second, the resulting object showed some complexity, possibly perceived as fuzziness. Hence, additional efforts were needed to clarify the course structure and its objectives, to facilitate the active role of learners in the acquisition of the expected skills.

\section{Authors' Contributions}

DIS, YC, CD, JLH, and NA wrote the protocol, planned the study, and supervised the work. DIS processed data under the supervision of YC, CD, and NA. AII, MLI, and HA have helped to results organization and interpretation. DIS and NA organized the manuscript and all co- authors reviewed the text.

\section{Acknowledgments}

The authors would like to thank all learners who participated to the evaluations, and the teaching staff. The research did not receive any specific grant from funding agencies in the public, commercial or not for profit sector, but was facilitated by University Dan Dicko Dankoulodo of Maradi, University of Liège and the Belgian "Académie de Recherche et d'Enseignement Supérieur, Commission de la Coopération au Développement."

\section{Competing Interests}

The authors declare that they have no competing interests.

\section{Publisher's Note}

Veterinary World (Publisher of International Journal of One Health) remains neutral with regard to jurisdictional claims in published institutional affiliation.

\section{References}

1. FAO-OIE-WHO Collaboration. (2010) Sharing Responsibilities and Coordinating Global Activities to Address Health Risks at the Animal-Human-Ecosystems Interfaces. A Tripartite Concept Note. World Health Organization, Geneva. p1-8.

2. De Onis, M. (2017) Child growth and development In: Semba, R.D. and Bloem, M.W., editors. Nutrition and Health in a Developing World. $2^{\text {nd }}$ ed. Springer, Totowa, New Jersey. p119-141

3. Sherman, D.M. (2005) Tending animals in the global village. J. Vet. Med. Educ., 32(1): 56-62.

4. Kahn, L.H., Kaplan, B., Monath, T.P. and Steele, J.H. (2008) Teaching one medicine, one health. Am. J. Med., 121(3): 169-170.

5. Kahn, L.H. (2011) The need for one health degree programs. Infect. Ecol. Epidemiol., 1(1): 7919.

6. Putra, T.A.T., Hezmee, M.N.M., Farhana, N.B., Hassim, H.A., Intan-Shameha, A.R., Lokman, I.H., Hamali, A.Y., Salisi, M.S., Ghani, A.A.A., Shahudin, M.S., Qayyum, M.A.L., Hafandi, A., Speare, R. and Fenwick, S.G. (2016) The application of one health concept to an outdoor problem-based learning activity for veterinary students. Vet. World, 9(9): 955-959.

7. Eveillard, M., Ruvoen, N., Lepelletier, D., Fradet, S., Couvreur, S., Krempf, M. and Magras, C. (2016) Integration of microbiology and infectious disease teaching courses in an interdisciplinary training programme (master level) centred on the One world, one health WHO concept. FEMS Microbiol. Lett., 363(9): 1-7.

8. Hemmingsen, A.M. (1960) Energy metabolism as related to body size and respiratory surfaces, and its evolution. Reports of The Steno Memorial Hospital, 13: 1-110.

9. Lejeune, C. (2014) Handbook for qualitative analysis: to analyze without counting nor classifying [Original text in French: Manuel d'Analyse Qualitative : Analyser Sans Compter ni Classer]. De Boeck, Louvain-la-Neuve. p1-152.

10. Blais, M. and Martineau, S. (2006) General inductive analysis: description of a process to make sense of raw data [Original text in French: L'analyse inductive générale: Description d'une démarche visant à donner un sens à des données brutes]. Rech Qual., 26(2), 1-18.

11. World Health Organization. (2018) Antimicrobial resistance and primary health care: Brief. In: Technical Series. World Health Organization, Geneva. p1-9.

12. Jacobs, H.H. (1989) Interdisciplinary Curriculum: Design and Implementation. Vol. 8. Association for Supervision and Curriculum Development, Alexandria, Virginia. p56-69.

13. Taylor, R.M. (2009) Defining, constructing and assessing learning outcomes. Rev. Sci. Tech., 28(2): 779-788.

14. Resnick, L.B. (1984) Toward a cognitive theory of instruction. In: Paris, S., Olson, G.M. and Stevenson, H.W., editors. Learning and Motivation in the Classroom. Taylor \& Francis, United Kingdom. p5-38.

15. Entwistle, N. and Ramsden, P. (2015) Understanding Student Learning (Routledge Revivals). Routledge, London, p1-244. 
16. Piaget, J. (1972) Epistemology of interdisciplinary relations [Original text in French: L'épistémologie des relations interdisciplinaires]. In: Ocde, C., editor. Interdisciplinarity ; Problems of teaching and research in the universities [Original text in French: L'interdisciplinarité. Problèmes d'Enseignement et de Recherche dans les Universités]
Organisation de Coopération et de Développement Économiques, Paris. p155-171.

17. Mélard, F., Denayer, D. and Semal, N. (2015) Public-basedlearning: The place of publics in exploring environmental controversies for pedagogical purposes. Int. J. Environ. Sci. Educ., 10(6): 905-920.

$* * * * * * * *$ 